\title{
Studies on Hypoxia
}

\section{EFFECTS OF ANOXIA ON DEVELOPING CONNECTIVE TISSUE CELLS IN RATS '}

\author{
JOON H. KIM AND SEONG S. HAN \\ Laboratory of Cell Biology, Dental Research Institute and Department of \\ Anatomy, University of Michigan
}

\begin{abstract}
The effect of anoxia on protein synthesis of developing connective tissue cells was studied by radioautography. Neonatal rats were subjected to anoxia for 20 minutes and were immediately injected with $3 \mu \mathrm{c} / \mathrm{gm}$ body weight of leucine$\mathrm{H}^{3}$ intraperitoneally. They were sacrificed at different intervals after injection. Control animals were handled identically, except that atmospheric air was made available. The heads of the animals were prepared for radioautography in the standard manner. The number of grains was counted over individual fibrobalsts, osteoblasts and chondrocytes of histologically comparable regions, and the data were statistically evaluated.

The number of grains per cell was significantly lower in experimental animals sacrificed at one hour after the anoxic treatment and leucine- $H^{3}$ administration. At this time, the average grain number per cell in the experimental animal was less than $50 \%$ of the control. The difference was about $20 \%$ by four hours and was negligible after 24 hours. The result is interpreted to indicate that the overall protein synthesis in connective tissues is immediately but temporarily suppressed by anoxia and that such suppression might lead to a later functional disturbance among these cells.
\end{abstract}

Traditionally the neurophysiologic aspects of the hypoxic effect have been extensively studied from the utilitarian point of view relative to anesthesia. The literature in this regard is rather voluminous. More recently, a number of studies on the development of foetuses exposed to hypoxia have demonstrated serious birth defects (Murakami, Kameyama and Kato, '56; Ingalls and Curley, '57; Degenhardt, '60; and Morawa and Han, '68). The teratological results so produced have led to the idea that the malformation was due to the excessive accumulation of lactic acid and thereby to a chemical upset of the milieu in which the foetal tissues were developing (Grabowski, '64).

In a previous study we noted, in addition to the skeletal deformities previously reported, a sharp reduction of basophilia and delayed differentiation of developing epithelial and connective tissue cells (Morawa and Han, '68). This was thought to be due to a sustained suppression of protein synthesis caused by a single insult given during the prenatal period. Consequently, we performed experiments aimed at illuminating the effects of prenatal exposure to anoxia on protein biosynthesis in rapidly growing cells during the immedi- ate postnatal period (Han and Kim, '69). The results from these experiments indicated that there was a significant drop in the rate of labelled amino acid incorporation into a variety of cells, including connective tissue cells.

In contrast to these results, cytologic studies dealing with the neonates subjected to anoxia within hours of birth did not reveal any notable change in the appearance of certain protein-producing cells, namely fibroblasts, osteoblasts and odontoblasts (Smith and Han, '68). However, a study of the protein synthesis (leucine$\mathrm{H}^{3}$ incorporation) in salivary glands from similarly treated neonates showed a dramatically reduced incorporation of the labelled amino acid as early as 60 minutes after anoxic exposure (Kim and Han, '69). This early reduction of leucine- $\mathrm{H}^{3}$ incorporation is in sharp contrast to the previously observed effect on the production of consecutive tissue proteins (proline- $\mathrm{H}^{3}$ incorporation) that showed the greatest reduction at 24 hours (Smith and Han, '68).

The purpose of this experiment was to study, by means of quantitative radioau-

Received May 19, '69. Accepted July 10,'69.

1 Supported in part by Grants HD-03147, DE-02311 and DE-02731 from the National Institutes of Health, U.S. Public Health Service. 
tography, the nature and extent of the immediate effect of anoxia on overall protein synthesis in fibroblasts, osteoblasts and chondrocytes of rat neonates.

\section{MATERIALS AND METHODS}

Experimental design. New-born SpragueDawley rats from an inbred colony were used throughout the experiment. They were subjected to anoxia for a period of 20 minutes by residence in a bell jar which was flushed with a continued flow of purified nitrogen. The oxygen content in the bell jar fell rapidly, within two minutes, to 30 to $40 \mathrm{ppm}$, as indicated by a Westinghouse oxygen analyzer, and was maintained at this low level for the rest of the time. Immediately after the anoxic period of time the rats were given intraperitoneally $3 \mu \mathrm{c}$ of DL-leucine-4, $5-\mathrm{H}^{3}$ per gm of body weight. The specific activity of the leucine was 5 curies per $\mathrm{mM}$. The same number of control animals was handled in an identical manner, except that during their residence in the bell jar the latter was continuously flushed with fresh air. Animals were sacrificed in pairs at $15 \mathrm{~min}$ utes and at 1, 4, 24, 48 and 72 hours after the injection of the labeled amino acid. Three identical experiments were carried out.

Preparation for radioautography. Animals were sacrificed by decapitation. The brain was removed after the calvarium was excised. The head was then sectioned through the mid-sagittal plane and fixed in Bouin's solution for 48 hours. During double-embedding in parlodion and paraplast in a routine manner the tissue was so oriented as to allow the sections to be made through the molar region of the developing maxillary arch. Serial sections, $6 \mu$ in thickness, were mounted on $1 \times 3$ inch microscope slides which had been pretreated with an adhesive solution consisting of $0.5 \%$ pure gelatin, $0.05 \%$ of chromium potassium sulphate in distilled water.

Five sets of slides, having comparable histological areas, were coated by dipping into Kodak NTB-3 emulsion at $45^{\circ} \mathrm{C}$ in total darkness. The slides were then placed on end on a wooden rack for 15 minutes in an oven set at $45^{\circ} \mathrm{C}$. After drying, the slides were placed in an air-tight box containing small packets of Drierite, shielded by wrapping with two layers of lead sheet, and wrapped with an additional layer of light-tight paper. They were sealed in a plastic bag in which Drierite packets were placed, and were kept in a refrigerator at $4^{\circ} \mathrm{C}$ for a period of five weeks.

At the end of the exposure period the slides were developed in 2, 4-diaminophenol dihydrochloride for one minute in complete darkness. After fixation in Kodak Rapid Fixer for two minutes and washing, the slides were stained in Harris hemotoxylin and alcoholic eosin $\mathrm{Y}$. The average number of grains over each cell type was obtained by counting approximately 500 cells per animal. In all, over 15,000 cells were examined. These data were subjected to the student $t$ test by using a computer program provided by the University of Michigan Terminal System IBM 7090.

\section{RESULTS AND OBSERVATIONS}

Little difference in cytological appearance could be discerned between anoxic and control rats throughout the experimental period. However, the amount and distribution of radioautographic grains over the matrices elucidated well the cumulative effects on secretory processes.

\section{The Fibroblast}

Depending upon the region the fibroblasts showed a wide range of average grain numbers. For instance, the cells in the dental pulp and developing periodontal ligaments had fewer grains per cell than those located in the subcutaneous connective tissue. Differences were also noted among the fibroblasts present on the subcutaneous tissues of various regions. For this reason, only those fibroblasts that were located in the subcutaneous region covering the lower border of the mandible were selected for this presentation.

A summary of individual counts of silver grains over the fibroblasts is given in table 1 . It can be seen that in control animals there was a progressive increase in the grain number from 4.9 at 15 minutes to 10.7 and 15.3 at 60 minutes and four hours respectively. By 24 hours, the average number was 9.8 per cell, and remained at this value essentially for the following 
TABLE 1

Quantitative radioautography on effects of neonatal anoxia in rats Leucine- $\mathrm{H}^{3}$ incorporation by fibroblast ${ }^{1}$

\begin{tabular}{cccc}
\hline $\begin{array}{c}\text { Time after } \\
\mathbf{H}^{3} \text { injection }\end{array}$ & Treatment & $\begin{array}{c}\text { Mean grain no. } \\
\text { (S.D.) }\end{array}$ & Probability \\
\hline \multirow{2}{*}{15 minutes } & Anoxia & $3.72( \pm 0.77)$ & $\mathrm{P}<0.001$ \\
& Control & $4.90( \pm 0.94)$ & \\
60 minutes & Anoxia & $4.86( \pm 1.39)$ & $\mathbf{P} 0.001$ \\
& Control & $10.68( \pm 1.73)$ & $\mathbf{P}<0.01$ \\
4 hours & Anoxia & $13.86( \pm 1.81)$ & \\
& Control & $15.32( \pm 1.99)$ & $\mathbf{P}<0.1$ \\
24 hours & Anoxia & $9.00( \pm 1.50)$ & \\
& Control & $9.82( \pm 1.51)$ & $\mathbf{P}<0.001$ \\
\hline
\end{tabular}

1 Neonates subjected to anoxia for 20 minutes and immediately injected with $3 \mu \mathrm{c} / \mathrm{gm} \mathrm{b} . \mathrm{w}$. of leucine-H $\mathrm{H}^{3}$ (Specific activity: $5 \mathrm{C} / \mathrm{mM}$ ). Radioautographic exposure, five weeks.

24 hours. On the other hand, the average number of grains per cell in the anoxic group was only 3.7 at 15 minutes, increased to 4.9 at 60 minutes, and then further increased to 13.9 by four hours after the injection. Thereafter, the average grain number dropped to 9.0 per cell, and no significant changes were noted in the following days.

Statistically, the differences at 15 and 60 minutes were significant at the level of $p<0.001$, whereas at four hours the difference between the average grain count was significant at $p<0.01$. The difference at 24 hours was only significant at the level of $p<0.1$, and the same tendency was observed throughout the rest of the experimental period.

The photomicrographs appearing in figures 1 through 8 illustrate and supplement the results obtained by the grain counting. Figures 1 and 2, which were from the experimental and control animals sacrificed at 15 minutes after the injection of labelled leucine, showed little difference on visual inspection. At 60 minutes, however, the number of grains superimposed upon these cells was definitely fewer in experimental as compared to control animals (figs. 3, 4 ). In addition, it was already evident by 60 minutes that there was an increasing number of grains localized in intercellular space, some distance away from the cell body. This point was even clearer in the pairs sacrificed at four hours (figs. 5, 6), and at 24 hours (figs. 7, 8), following the injection. Thus, the grain number over the intercellular space is definitely greater in the control tissue of both 4- and 24-hour animals, despite the relatively large number of grains over the cells in experimental animals at this time.

\section{The Osteoblast}

In table 2 the counts of silver grains over osteoblasts are summarized. Recognizing the large regional variation in osteogenic activities of developing bones, we have limited our observations to the lower border of mandible directly under the forming molar teeth. It is pertinent that the pattern of changes of average grains per cell in the control animals was similar to that seen in the fibroblasts.

There was a difference between the experimental and control value throughout the first four hours, and the level of significance in all of these periods was $p<$ 0.001 . As was true in the case of fibroblasts, the greatest difference was observed at 60 minutes after the injection, namely 10.7 grains per cell in the control and 6.0 grains per cell in the experimental. The slight differences observed in the average value at 24 hours and at 48 hours were statistically insignificant in this case.

Figures 9 through 16 provide pictorial supports for the quantitative data. At 15 minutes (figs. 9, 10) the small difference was not readily noticeable in actual photo- 
TABLE 2

Quantitative radioautography on effects of neonatal anoxia in rats Leucine- $\mathrm{H}^{3}$ incorporation by osteoblast ${ }^{\mathrm{I}}$

\begin{tabular}{cccc}
\hline $\begin{array}{c}\text { Time after } \\
\mathbf{H}^{3} \text { injection }\end{array}$ & Treatment & $\begin{array}{c}\text { Mean grain no. } \\
\text { (S.D.) }\end{array}$ & Probability \\
\hline \multirow{2}{*}{15 minutes } & Anoxia & $2.5( \pm 0.81)$ & $\mathrm{P}<0.001$ \\
& Control & $4.62( \pm 0.98)$ & \\
60 minutes & Anoxia & $5.96( \pm 1.04)$ & $\mathbf{P}<0.001$ \\
& Control & $10.67( \pm 2.01)$ & $\mathrm{P}<0.001$ \\
4 hours & Anoxia & $9.33( \pm 1.96)$ & \\
& Control & $11.29( \pm 2.42)$ & $\mathrm{P}<0.6$ \\
24 hours & Anoxia & $12.13( \pm 1.82)$ & \\
& Control & $12.37( \pm 1.67)$ & $\mathbf{P}<0.7$ \\
\hline
\end{tabular}

1 Neonates subjected to anoxia for 20 minutes and immediately injected with $3 \mu \mathrm{c} / \mathrm{gm} \mathrm{b} . \mathrm{w}$. of leucine-H3 ${ }^{3}$ (Specific activity: $5 \mathrm{C} / \mathbf{m M}$ ). Radioautographic exposure, five weeks.

micrographic fields. By 60 minutes, however, the cells of the controls (fig. 12) showed far more grains than those of the experimental animals (fig. 11). In figures 13 and 14, which were from the experimental and control animals at four hours, a clear difference was discerned in the extracellular grain numbers as in the case of the fibroblasts. Although the average intracellular grains per cell did not indicate a statistically significant difference $(\mathrm{p}<0.6)$ the animals sacrificed 24 hours after the injection of the radioactive amino acid demonstrated a clear difference in the amount of extracellularly located grains (figs. 15, 16).

\section{The chondrocyte}

In the new-born rat a fairly large amount of chondrogenic tissues are notable in the spheno-occipital region of the cranial base. By selecting histologically comparable areas of such chondroid masses, meaningful quantitative efforts could be made. In table 3 are recorded the results of grain counts made in these chondroid tissues. The change in average number of grains per control chondrocyte at different intervals paralleled generally that of the fibroblast and osteoblast and showed a rapid increase during the first four hours. There were significant differences between experimental and control animals except in those that were sacrificed at 48 and 72 hours. The level of significance in these periods was better than $\mathrm{p}<0.01$.
As shown in photomicrographs it was evident that an increased number of extracellular grains was localized in the control animals sacrificed at one hour (fig. 20) and four hours as compared to the $15 \mathrm{~min}$ ute-control (fig. 18). Throughout, the number of grains seen extracellularly was lower in the experimental animals than that of the control. By 24 hours the intercellular grains in the experimental animal (fig. 23) had increased considerably and the net difference between the experimental and control (fig. 24) appeared to be reduced.

\section{DISCUSSION}

Despite the problems relative to the fixation of free precursors or conversely leeching out of synthesized materials during the course of preparation, quantitative radioautography has been successfully applied to many problems that require the localization of radioactive precursors being incorporated into proteins at histological and cytological levels (Warshawsky, Leblond and Droz, '63; Young and Greulich, '63; Ross and Benditt, '62; Han, '67; and many others). Although we have used, as have others, $1 \mu$-thick sections of epoxide-embedded materials for radioautographic quantitation of soft tissues, the limitation of the block size creates a serious problem in attempting to extend the same technique to studies of the hard tissues of craniofacial regions, which are necessarily large and have a marked func- 
TABLE 3

Quantitative radioautography on effects of neonatal anoxia in rats Leucine- $H^{3}$ incorporation by chondrocytes of nasosphenoidal region ${ }^{1}$

\begin{tabular}{cccc}
\hline $\begin{array}{c}\text { Time after } \\
\mathrm{H}^{3} \text { injection }\end{array}$ & Treatment & $\begin{array}{c}\text { Mean grain no. } \\
(\mathrm{S.D} .)\end{array}$ & Probability \\
\hline \multirow{2}{*}{15 minutes } & Anoxia & $2.89( \pm 0.94)$ & $\mathrm{P}<0.001$ \\
& Control & $4.84( \pm 1.26)$ & $\mathrm{P}<0.001$ \\
60 minutes & Anoxia & $4.08( \pm 0.88)$ & \\
& Control & $10.37( \pm 2.24)$ & $\mathrm{P}<0.01$ \\
4 hours & Anoxia & $11.79( \pm 1.93)$ & $\mathrm{P}<0.001$ \\
& Control & $13.25( \pm 2.07)$ & \\
24 hours & Anoxia & $9.33( \pm 2.19)$ & $\mathrm{P}<0.3$ \\
& Control & $12.00( \pm 1.80)$ & $8.63( \pm 1.77)$ \\
\hline
\end{tabular}

1 Neonates subjected to anoxia for 20 minutes and immediately injected with $3 \mu \mathrm{c} / \mathrm{gm} \mathrm{b} . \mathrm{w}$. of leucine-H ${ }^{3}$ (Specífic activity: $5 \mathrm{C} / \mathrm{mM}$ ). Radioautogxaphic exposure, five weeks.

tional and structural heterogeneity among cells present in different regions. Under these circumstances, the relatively thick sections of paraffin-embedded materials used in this study represent one of the best, if not the only, method of studying the modification of the hard tissue metabolism at the level of individual cells.

It should be noted that, although statistically significant differences were present in all animals sacrificed at 15 minutes, one hour and four hours after anoxic exposure, the difference was the greatest at $60 \mathrm{~min}$ utes following the insult. The fact that such differences were largely insignificant after 24 hours of the insult suggests the transient nature of the suppression of leucine- $\mathrm{H}^{3}$ incorporation. In this connection it is of interest to compare the data from the present study to those of our previous work in which the incorporation of proline- $\mathrm{H}^{3}$ into the secretory proteins was studied in similar types of cells (Smith and Han, '68). Of the cells studied, which included osteoblasts and fibroblasts, the incorporation of proline- $\mathrm{H}^{3}$ was suppressed to the greatest degree at 24 hours following the anoxia, and only a small suppression was noted at one and six hours after the insult. This delay in maximum suppression of proline- $\mathrm{H}^{3}$ incorporation is in sharp contrast with the early reduction of leucine- $\mathrm{H}^{3}$ incorporation observed in this study.

Since proline- $\mathrm{H}^{3}$ is incorporated into collagen and other proteins of the connective tissue matrix the delayed effect might be taken as indicative of an earlier effect upon the developing intracellular machinery necessary for secretory protein synthesis, such as the endoplasmic reticulum, Golgi apparatus and ribosomes. It is possible that the direct effect of anoxia on the overall protein synthesis by these cells is recovered to a near-normal level by 24 hours after the insult, despite a markedly reduced incorporation of amino acids into secretory proteins. This particular point should remain as a question to be supplemented by future experiments, as these two experiments were done under similar but not identical conditions.

The fact that the synthesis of proteins in rapidly growing neonates is drastically reduced following a brief exposure to anoxia provides us with another point that should be considered in conjunction with the etiology of malformation in developing animals exposed to hypoxic insult. As mentioned earlier, previous studies dealing with prenatal animals have suggested that the hypoxia related deformities malformation might be due to the accumulation of lactic acid and interference of tissue growth by such an accumulation of the lactic acid (Ingalls and Curley, '57; Grabowski, '64). While this probably is true, the serious, though transient, impairment of protein biosynthesis in various connective tissue cells at a crucial time during cellular differentiation might be responsible for the derangement of the pattern of 
sequential enzyme differentiation of various body regions. The importance of maintaining such a pattern of differentiation for the normal growth of an individual organism cannot be overemphasized, inasmuch as the normal differentiation and growth of cells are implemented by the coordinated evolution of enzymes which are proteinaceous. In this sense the present results augment the previously expressed concepts, and offer a complementary alternative to the mechanistic view.

\section{LITERATURE CITED}

Degenhardt, K. H. 1960 Cranio-facial dysplasia induced by oxygen deficiency in rabbits. Biologia. Neonat., 2: 93-104.

Grabowski, C. T. 1964 The aetiology of hypoxia induced malformations in the chick embryo. J. Exp. Zool., 157: 307-326.

Han, S. S. 1967 An electron microscopic and radioautographic study of the rat parotid gland after actinomycin $\mathrm{D}$ administration. Am. J. Anat., 120: 161-184.

Han, S. S., and J. H. Kim 1968 Studies on hypoxia VI. Effects of prenatal exposure on leucine- $\mathrm{H}^{3}$ incorporation by the pancreas and submandibular gland in the rat. In preparation.

Ingalls, T. H., and F. J. Curley 1957 Principles governing the genesis of congenital mal- formation induced in mice by hypoxia. New Eng. J. Med., 257: 1121-1127.

Kim, J. H., and S. S. Han 1968 Studies on hypoxia, III. Effects of leucine- $\mathrm{H}^{3}$ incorporation by submandibular gland cells of rat neonates. Proc. Soc. Exp. Biol. and Med., 130: 470-473.

Morawa, A. P., and S. S. Han 1968 Studies on hypoxia, I. Gross and histological influences of maternal anoxia upon the developing rat foetus. Archs. Oral Biol,, 13: 745-754.

Murakami, U., Y. Kameyama and T. Kato 1956 Effects of maternal anoxia upon the development of embryos. Rep. Res. Inst. Environ. Med., Nagoya Univ., 55: 76-87.

Ross, R., and E. P. Benditt 1962 Wound healing and collagen formation, II. Fine structure in experimental scurvy. J. Cell Biol., 12: 533551.

Smith, D. M., and S. S. Han 1968 Studies on hypoxia, II. Auotradiographic quantitation of proline- $\mathrm{H}^{3}$ incorporation by connective tissue cells of the neonatal hamster. J. Dent. Res., 47: 244-251.

Warshawsky, H., C. P. Leblond and B. Droz 1963 Synthesis and migration of proteins in the cells of the exocrine pancreas as revealed by specific activity determination from radioautographs. J. Cell Biol., 16:1-21.

Young, R. W., and R. C. Greulich 1963 Distinctive autoradiographic patterns of glycine incorporation in rat enamel and dentine matrices. Archs. Oral Biol., 8: 509-521.

\section{PLATE 1}

\section{EXPLANATION OF FIGURES}

Figs. 1-8 Radioautographs of the subcutaneous connective tissue from normal and anoxia-treated animals injected with $3 \mu \mathrm{c} / \mathrm{gm}$ body weight of leucine- $\mathrm{H}^{3}$. The photographs on the left column represent the experimental animals, while the ones on the right column are from the control animals sacrificed at the same intervals corresponding to those on the left. All figures magnified $750 \times$.

1 Experimental rat sacrificed at 15 minutes.

2 Control rat sacrificed at 15 minutes. Only a few grains are localized over individual fibroblasts.

3 Experimental animal sacrificed at 60 minutes after the injection. There is no increase in the number of grains as compared to the experimental rat sacrificed at 15 minutes.

4 Control animal sacrificed at 60 minutes. Compared to figure 2 there is a notable increase in the intracellular and extracellular grains.

5 Experimental animal sacrificed at four hours. Note that the number of intracellular grains is considerably increased from earlier intervals.

6 Control rat sacrificed at four hours. The number of grains superimposed upon individual cells is about the same as that of the experimental. However, a greater number of extracellular grains is observed.

7-8 Experimental and control animals sacrificed at 24 hours. The number of intracellular grains is about the same between the two photomicrographs except that in the control animal there is a greater number of extracellular grains. 


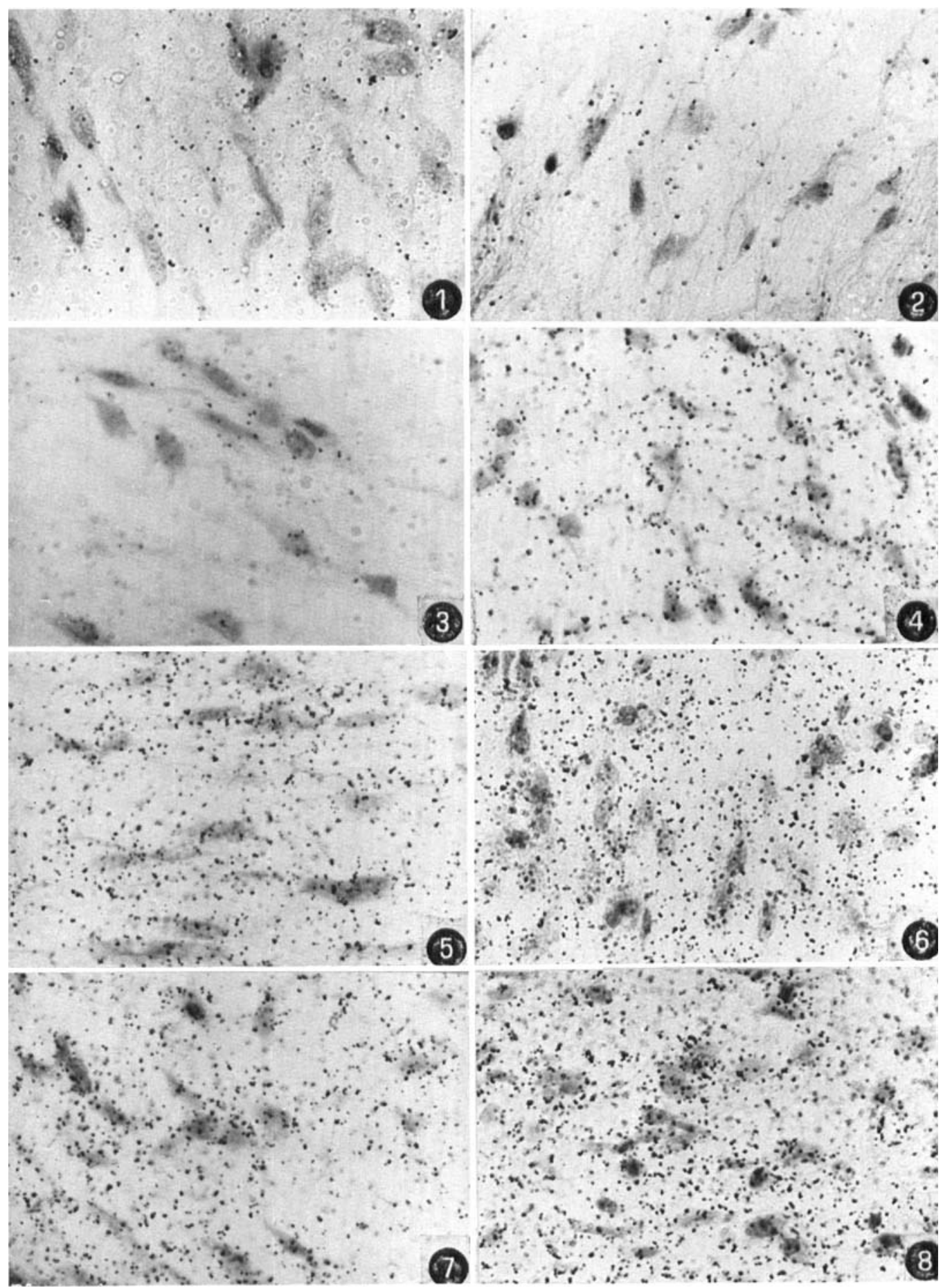




\section{PLATE 2}

EXPLANATION OF FIGURES

Figs. 9-16. Radioautographs of the osteogenic region along the lower border of the mandible in normal and anoxia-treated rats injected with $3 \mu \mathrm{c} / \mathrm{gm}$ body weight of leucine- $\mathrm{H}^{3}$. The photographs on the left column represent the exeprimenta] animals, whereas the ones on the right are from the control rats sacrificed at the same intervals corresponding to those on the left. All figures magnified $750 \times$.

9 Experimental animal sacrificed at 15 minutes.

10 Control animal sacrificed at 15 minutes. Note the relative paucity of grains in both the experimental and control rats.

11 Experimental animai sacrificed at 60 minutes.

12 Control animal sacrificed at 60 minutes. Compared to figure 11 a much larger number of intracellular grains is evident. The number of extracellular grains is also increased.

13 Experimental animal sacrificed at 4 hours. The number of intracellular grains is increased over that shown in figure 11.

14 Control animal sacrificed at 4 hours. The number of extracellular grains is increased over that seen in the control at 60 minutes and is greater than that of the experimental.

15-16 Experimental and control animals sacrificed at 24 hours. As is true in the case of fibroblasts, the number of extracellular grains is greater in the control animal. 


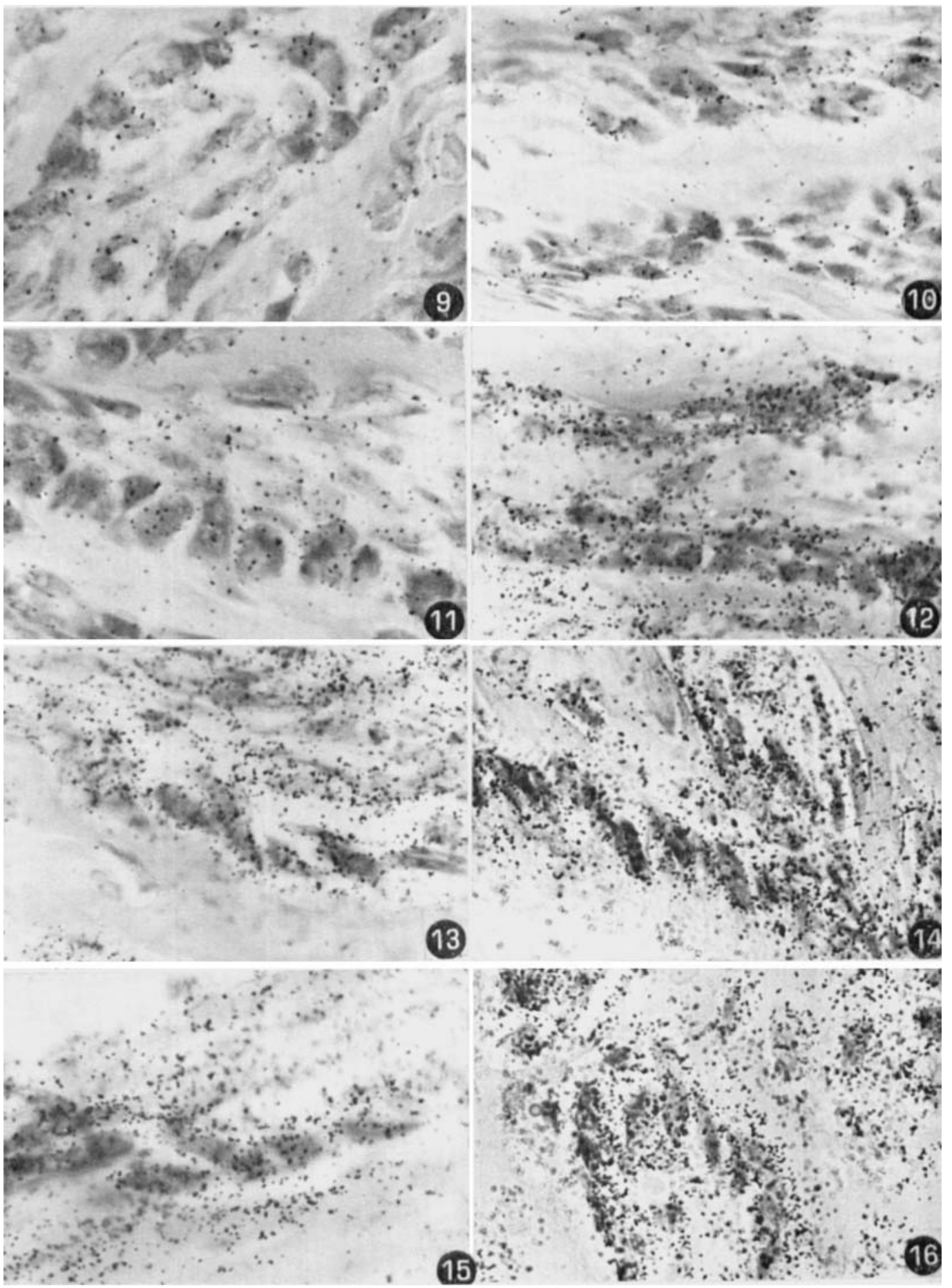




\section{PLATE 3}

EXPLANATION OF FIGURES

Figs. 17-24. Radioautographs of chondroid mass of the spheno-occipital region of normal and anoxia-subjected neonatal rats injected with $3 \mu \mathrm{c} / \mathrm{gm}$ body weight of leucine- $\mathrm{H}^{3}$. The photographs on the left column represent fields from anoxic animals, whereas the ones on the right depict comparable controls. All figures magnified at $750 \times$.

17 Experimental animals sacrificed at 15 minutes. Only a few grains are seen over individual lacunae.

18 Control animal sacrificed at 15 minutes after the injection. The number of grains is slightly larger than figure 17.

19 Experimental animal sacrificed at 60 minutes. Again only a small number of intracellular granules is visible.

20 Control animal sacrificed at 60 minutes. Compared to figure 19 a larger number of intracellular and extracellular grains is noted.

21 Experimental animal sacrificed at 4 hours. The number of intracellular grains is notably increased over that seen at earlier intervals and occasional extracellular grains are observed.

22 Control animal sacrificed at four hours. In addition to a considerable number of intracellular grains, a large number of extracellular grains is visible, although many of the extracellular grains are out of focus.

23-24 Radioautographs of experimental and control animals sacrificed at 24 hours. Compared to the control (fig. 24), fewer extracellular grains are present in the experimental (fig. 23). 


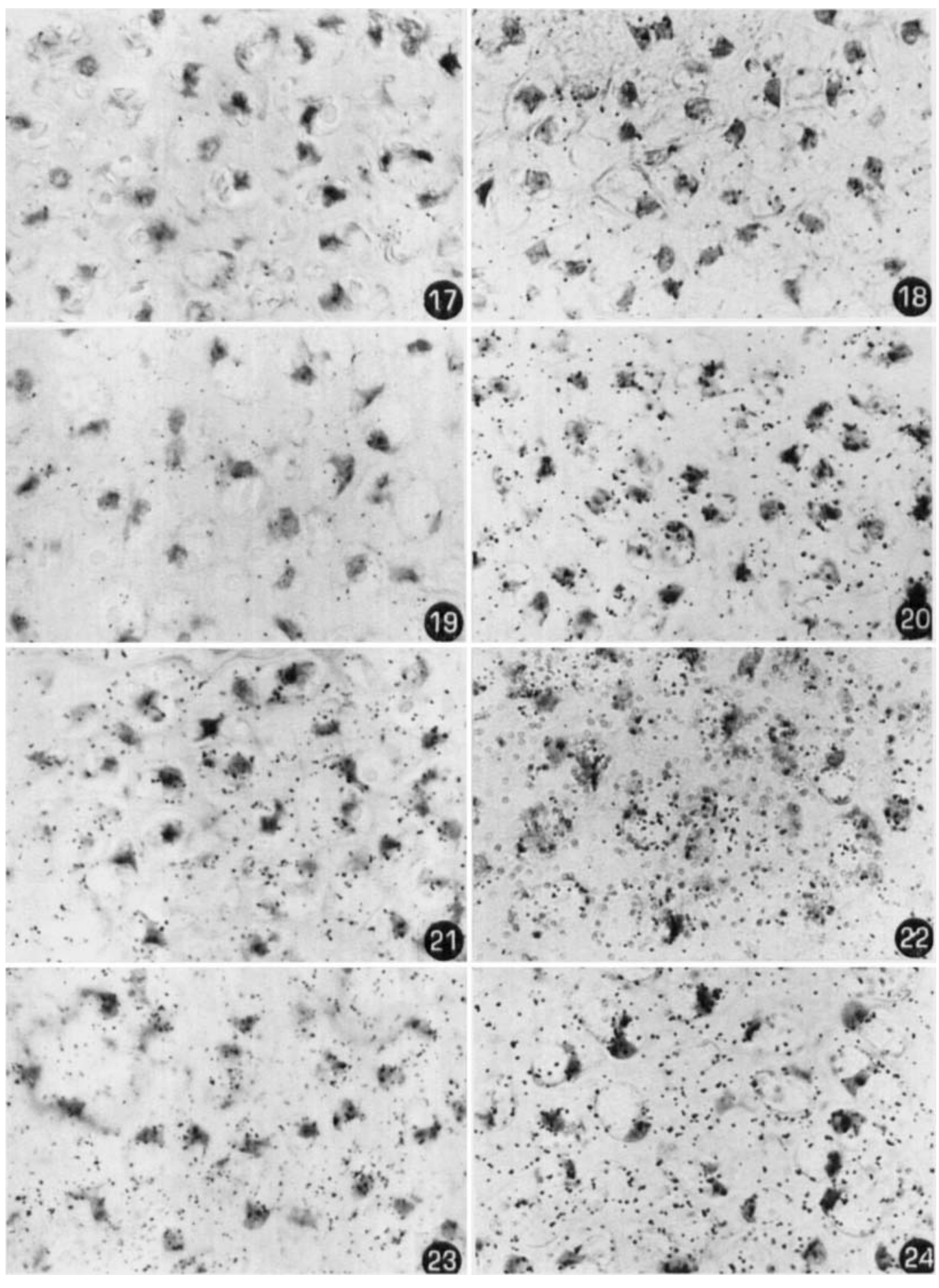

